\title{
Distribution of Alox15 in the Rat Brain and Its Role in Prefrontal Cortical Resolvin D1 Formation and Spatial Working Memory
}

\author{
Suku-Maran Shalini ${ }^{1,2}$ - Christabel Fung-Yih Ho ${ }^{1,2} \cdot$ Yee-Kong $\mathrm{Ng}^{1} \cdot \mathrm{Jie}^{\mathrm{X}} \mathrm{Xin} \mathrm{Tong}^{1}$ • \\ Eng-Shi Ong ${ }^{3}$ • Deron R. Herr ${ }^{4}$ - Gavin S. Dawe ${ }^{2,4}$ • Wei-Yi Ong ${ }^{1,2}$
}

Received: 12 October 2016 / Accepted: 18 January 2017 / Published online: 8 February 2017

(C) The Author(s) 2017. This article is published with open access at Springerlink.com

\begin{abstract}
Docosahexaenoic acid (DHA) is enriched in membrane phospholipids of the central nervous system (CNS) and has a role in aging and neuropsychiatric disorders. DHA is metabolized by the enzyme Alox15 to 17S-hydroxy-DHA, which is then converted to 7S-hydroperoxy,17S-hydroxyDHA by a 5-lipoxygenase, and thence via epoxy intermediates to the anti-inflammatory molecule, resolvin D1 (RvD1 or 7S,8R,17S-trihydroxy-docosa-Z,9E,11E,13Z,15E,19Zhexaenoic acid). In this study, we investigated the distribution and function of Alox15 in the CNS. RT-PCR of the CNS showed that the prefrontal cortex exhibits the highest Alox15 mRNA expression level, followed by the parietal association cortex and secondary auditory cortex, olfactory bulb, motor and somatosensory cortices, and the hippocampus. Western blot analysis was consistent with RT-PCR data, in that the prefrontal cortex, cerebral cortex, hippocampus, and olfactory bulb had high Alox15 protein expression. Immunohistochemistry showed moderate staining in the olfactory bulb, cerebral cortex, septum, striatum, cerebellar cortex, cochlear nuclei, spinal trigeminal nucleus, and dorsal horn of the spinal cord. Immuno-electron microscopy showed localization of Alox15 in dendrites, in the
\end{abstract}

Wei-Yi Ong

wei_yi_ong@nuhs.edu.sg

Department of Anatomy, National University of Singapore, Singapore 119260, Singapore

2 Neurobiology and Ageing Research Programme, National University of Singapore, Singapore 119260, Singapore

3 Department of Science, Singapore University of Technology and Design, Singapore 487372, Singapore

4 Department of Pharmacology, National University of Singapore, Singapore 119260, Singapore prefrontal cortex. Liquid chromatography mass spectrometry analysis showed significant decrease in resolvin D1 levels in the prefrontal cortex after inhibition or antisense knockdown of Alox15. Alox15 inhibition or antisense knockdown in the prefrontal cortex also blocked long-term potentiation of the hippocampo-prefrontal cortex pathway and increased errors in alternation, in the T-maze test. They indicate that Alox15 processing of DHA contributes to production of resolvin D1 and LTP at hippocampo-prefrontal cortical synapses and associated spatial working memory performance. Together, results provide evidence for a key role of anti-inflammatory molecules generated by Alox 15 and DHA, such as resolvin D1, in memory. They suggest that neuroinflammatory brain disorders and chronic neurodegeneration may 'drain' anti-inflammatory molecules that are necessary for normal neuronal signaling, and compromise cognition.

Keywords 15 Lipoxygenase $1 \cdot$ Learning and memory · Long-term potentiation $\cdot$ Spatial working memory $\cdot$ Synaptic plasticity $\cdot$ DHA $\cdot$ Resolvin D1

$\begin{array}{ll}\text { Abbreviations } \\ \text { AA } & \text { Arachidonic acid } \\ \text { AD } & \text { Alzheimer's disease } \\ \text { CNS } & \text { Central nervous system } \\ \text { DHA } & \text { Docosahexanoic acid } \\ \text { DMSO } & \text { Dimethyl sulfoxide } \\ \text { fEPSP } & \text { Field excitatory post-synaptic potential } \\ \text { HFS } & \text { High-frequency stimulation } \\ \text { HPC } & \text { Hippocampus } \\ \text { IOC } & \text { Input/output curve } \\ \text { iPLA } & \text { Calcium independent phospholipase } \mathrm{A}_{2} \\ \text { LTP } & \text { Long-term potentiation }\end{array}$




$\begin{array}{ll}\text { NPD1 } & \text { Neuroprotectin D1 } \\ \text { PLA }_{2} & \text { Phospholipase } \mathrm{A}_{2} \\ \text { PUFA } & \text { Polyunsaturated fatty acid } \\ \text { RvD1 } & \text { Resolvin D1 } \\ \text { RvD1 } & \text { Resolvin D2 } \\ \text { SDS- } & \text { Sodium dodecyl sulfate polyacrylamide gel } \\ \text { PAGE } & \text { electrophoresis }\end{array}$

\section{Introduction}

Lipoxygenases (EC 1.13.11) are a superfamily of oxidoreductive enzymes that contain a nonheme iron and catalyze the incorporation of two atoms of oxygen into a single donor, specifically polyunsaturated fatty acids (PUFA) containing a cis,cis-1,4pentadiene structure $[1,2]$. The dioxygenation of PUFAs such as docosahexaenoic acid (DHA) and arachidonic acid (AA) by lipoxygenases generates fatty acid hydroperoxy products $[1,3]$. Of the lipoxygenases, 15-lipoxygenase catalyzes the direct dioxygenation of phospholipids and cholesterol esters of biological membranes and plasma lipoproteins [4]. There are two isoforms of the 15-lipoxygenase enzyme, the type 1 (Alox15), also known in rodents as leukocyte-type and in humans as reticulocyte-type, and type 2 (Alox15B) [5], both of which regulate the production of fatty acid hydroperoxides [6, 7]. Human reticulocyte-type Alox15, also known as arachidonate 15lipoxygenase (Alox15), is a $75 \mathrm{kDa}$ enzyme made up of a single chain of amino acids. The Alox15 gene is found on human chromosome 17. It has 10 tandem repeats of a motif rich in pyrimidine in its $3^{\prime}$-untranslated region, which regulate enzyme expression inhibiting Alox15 translation through association with the regulatory proteins, heterogeneous ribonucleoprotein $\mathrm{K}$, and heterogeneous ribonucleoprotein E1 [8].

Alox15 metabolizes DHA to 17S-hydroxy-DHA, which is then converted to 7S-hydroperoxy,17S-hydroxy-DHA by a 5lipoxygenase, and thence via epoxy intermediates to resolvin D 1 (RvD1 or 7S, 8R, 17S-trihydroxy-docosaZ,9E,11E,13Z,15E,19Z-hexaenoic acid) and resolvin D2 (RvD2 or 7S, 16R, 17S trihydroxy-docosa4Z,8E,10Z,12E,14E,19Z-hexaenoic acid) [9]. The Alox15 product 17S-hydroxy-DHA can also be converted to a 16(17)-epoxide and then to the 10,17-dihydroxy docosatriene termed neuroprotectin D1 (NPD1) [9]. These lipid mediators are involved in the removal of inflammatory cells and restoration of tissue integrity during resolution of inflammation [10]. They can modulate the effects of proinflammatory eicosanoids derived from AA [11], reduce leukocyte trafficking, and downregulate cytokine expression [11]. Alox15 also plays a role in supraspinal antinociception originating in the prefrontal cortex [12], but thus far, little is known about the distribution and function of the enzyme in the CNS.

The hippocampus and prefrontal cortex function together jointly as a memory system enabling working memory and consolidation of contextual information [13]. DHA and its docosanoids are beneficial for these cognitive functions [14]. DHA, which is a substrate of Alox15, is enriched in membrane phospholipids of the central nervous system (CNS) [15], and disturbances in its metabolism could play a role in aging and neuropsychiatric disorders [15-17]. DHA is released from membrane phospholipids by calciumindependent phospholipase $\mathrm{A}_{2}\left(\mathrm{PLLA}_{2}\right)$ [18-21]. Decreased iPLA $A_{2}$ activity has been detected in the prefrontal cortex of patients with Alzheimer's disease (AD) [22]. iPLA 2 plays a role in synaptic plasticity, and inhibition or antisense oligonucleotide knockdown of iPLA $_{2}$ prevents induction of hippocampo-prefrontal cortex long-term potentiation (LTP) [23]. Selective inhibitors of iPLA $A_{2}$ prevent induction of LTP in hippocampal slices [24]. DHA rescues the impairment caused by an $\mathrm{iPLA}_{2}$ inhibitor $[25,26]$ while its supplementation improves learning and memory in patients with agerelated cognitive decline [27] and protects from amyloid and dendritic pathology in AD model mice [28-30].

We hypothesize that DHA and its metabolites that are produced by the action of iPLA $\mathrm{P}_{2}$ are important for hippocampoprefrontal cortex synaptic plasticity and prefrontal cortexdependent working memory. The present study was carried out to elucidate the relative expression of Alox 15 across brain regions and its possible role in prefrontal cortical function.

\section{Methods and Materials}

\section{Animals}

Adult male Wistar rats (250-300 g) were purchased from InVivos, Singapore, and housed in temperature controlled $\left(23 \pm 1{ }^{\circ} \mathrm{C}\right)$, individually ventilated cages on a 12 -h light-dark cycle (7AM-7PM) with access to food and water. Rats were acclimatized for 4 days before the start of experiments. All procedures were in accordance with the Principles of Laboratory Animal Care and approved by the Institutional Animal Care and Use Committee of the National University of Singapore.

\section{Chemicals}

The specific Alox15 inhibitor, PD146176, was purchased from Cayman Chemicals (Ann Arbor, Michigan, USA) and was diluted in the vehicle dimethyl sulfoxide (DMSO) (Sigma, St. Louis, USA).

\section{Antisense Oligonucleotide}

The antisense oligonucleotide used was a 16-base oligonucleotide (5'-CACATGGTGATGAAGT-3'). This has been shown to effectively knock down Alox15 expression in the mouse 
brain [12], but is also suitable for the rat brain. Scrambled sense oligonucleotide was used as a control (5'-CACG TCTATACACCAC- $3^{\prime}$ ). Both antisense and sense oligonucleotides contained phosphorothioate linkages to prevent nuclease degradation (IBA, Germany). Solutions of $200 \mu \mathrm{M}$ were prepared by dissolving lyophilized material in nuclease-free water.

\section{Stereotaxic Injection}

Rats were anesthetized with the inhalational anesthetic isoflurane (Sigma-Aldrich, St Louis, USA) - up to 5\% for induction, $1-3 \%$ for maintenance using a precision vaporizer and mounted on a stereotaxic frame (Stoelting, Wood Dale, USA). A midline incision was made on the scalp and small craniotomies performed over the injection sites, $4.0 \mathrm{~mm}$ anterior and $1.5 \mathrm{~mm}$ lateral to the bregma on both sides, and $2.0 \mathrm{~mm}$ from the surface of the cortex. These coordinates correspond to the prefrontal cortex and were determined using the rat brain atlas of Paxinos and Watson 1998 [31]. Five microliters of either vehicle control (DMSO) or Alox 15 inhibitor in DMSO $(40 \mathrm{mM})$ and $2 \mu \mathrm{l}$ of antisense oligonucleotide or scrambled sense oligonucleotide were bilaterally injected into the cortex, at a rate of $5 \mathrm{~min}$ per injection. Injections were carried out in a blinded manner to reduce experimenter bias.

\section{Real-Time Reverse Transcriptase Polymerase Chain Reaction}

Six adult male Wistar rats were used per experiment for this portion of the study. Rats were deeply anesthetized with a ketamine/xylazine cocktail and sacrificed by decapitation. The ketamine/xylazine mixture used was prepared in saline [32] (7.5 ml ketamine (75 mg/kg), $5 \mathrm{ml}$ xylazine $(10 \mathrm{mg} / \mathrm{kg})$, in $7.5-\mathrm{ml} 0.9 \%$ sodium chloride solution). Ketamine used was obtained from Parnell Manufacturing Pte Ltd., Alexandria, New South Wales, Australia, while xylazine used was obtained from Ilium Xylazil, Troy Laboratories Pty Ltd., Glendenning, New South Wales, Australia. Various parts of the rat brain including olfactory bulb, prefrontal cortex, cortex 1 , cortex 2, striatum, thalamus/hypothalamus, hippocampus, cerebellum, and brainstem were dissected out, immersed in RNAlater ${ }^{\circledR}$ solution (Ambion, TX, USA), and snap frozen in liquid nitrogen. Anatomically, cortex 1 contains the primary and secondary motor cortex and the primary somatosensory cortex, whereas cortex 2 includes the parietal association cortex and secondary auditory cortex.

Total RNA was extracted using Trizol reagent (Invitrogen, CA, USA) according to (manufacturer's) protocol. RNeasy ${ }^{\circledR}$ Mini Kit (Qiagen, Inc., CA, USA) was used to purify the RNA. Samples were reverse transcribed using HighCapacity cDNA Reverse Transcription Kits (Applied Biosystems, CA, USA). Reaction conditions were $25^{\circ} \mathrm{C}$ for $10 \mathrm{~min}, 37^{\circ} \mathrm{C}$ for
$120 \mathrm{~min}$, and $85^{\circ} \mathrm{C}$ for $5 \mathrm{~s}$. Real-time PCR amplification was performed using a 7500 Real-time PCR system (Applied Biosystems) with TaqMan ${ }^{\circledR}$ Universal PCR Master Mix (Applied Biosystems), Alox5 (Rn00563172 m1), Alox12 (Rn01461082 m1), Alox15 (Rn00696151 m1), and $\beta$-actin probes (\#4352340E) (Applied Biosystems, CA, USA) according to the manufacturer's instructions. The PCR conditions were as follows: incubation at $50{ }^{\circ} \mathrm{C}$ for $2 \mathrm{~min}$ and $95{ }^{\circ} \mathrm{C}$ for $10 \mathrm{~min}$ followed by 40 cycles of $95^{\circ} \mathrm{C}$ for $15 \mathrm{~s}$ and $60^{\circ} \mathrm{C}$ for $1 \mathrm{~min}$. All reactions were carried out in triplicate. The threshold cycle $\left(\mathrm{C}_{\mathrm{T}}\right)$ was measured as the number of cycles in which the reporter fluorescence emission exceeds the preset threshold level. Amplified transcripts were quantified using the comparative $\mathrm{C}_{\mathrm{T}}$ method [33], with the formula for relative fold change $=2^{-\Delta \Delta \mathrm{CT}}$. The mean and standard error were then calculated.

\section{Western Blot}

Six adult male Wistar rats were used for the first portion of this study. Rats were deeply anesthetized with a ketamine/xylazine cocktail and sacrificed by decapitation. Various parts of the rat brain including olfactory bulb, prefrontal cortex, striatum, thalamus/hypothalamus, hippocampus, cerebellum, brainstem, and spinal cord were dissected out and snap frozen in liquid nitrogen.

Four adult male Wistar rats were used per group (scrambled sense and Alox15 antisense) for the second portion of this study. Rats that had been stereotaxically injected with scrambled sense or antisense oligonucleotides were deeply anesthetized with the ketamine/xylazine cocktail and sacrificed by decapitation 4 days after stereotaxic injection. The prefrontal cortices of these rats were dissected out and snap frozen in liquid nitrogen.

Tissues were homogenized using a Tissue Tearor ${ }^{\circledR}$ (Biospec, ITS Science and Medical, Singapore) in icecold buffer (M-Per mammalian protein extraction kit, $1 \mathrm{mM}$ EDTA and $0.25 \mathrm{mM}$ DTT). Homogenates were centrifuged at 13,000 rpm for $20 \mathrm{~min}$, and the supernatant collected. Protein concentration in the supernatant was determined using a Bio-Rad protein assay kit (Bio-Rad Laboratories, Hercules, USA). Proteins were resolved in $15 \%$ sodium dodecyl sulfate polyacrylamide gel (SDS-PAGE) under reducing conditions and subsequently electrotransferred to a PVDF membrane (Amersham Pharmacia Biotech, Little Chalfont, UK). The molecular weights of the proteins were determined using a Bio-Rad Prestained Protein Ladder (Bio-Rad Laboratories). Non-specific binding sites on the PVDF membrane were blocked by incubation with 5\% non-fat milk in Tris-buffered saline-Tween (TBST) for $1 \mathrm{~h}$. The PVDF membrane was then incubated overnight with an affinity-purified mouse 
monoclonal antibody to Alox15 (Abcam, Cambridge, UK, diluted 1:2000) in TBST with 5\% non-fat milk. The membrane was then washed in TBST and incubated with horseradish peroxidase conjugated horse anti-mouse IgG (ThermoFisher Scientific, Waltham, USA, diluted 1: 2000) for $1 \mathrm{~h}$ at room temperature. Immunoreactivity was visualized using an enhanced chemiluminescence kit (Pierce, Rockford, USA) according to the manufacturer's instructions. Band intensities were quantified by densitometric analysis.

\section{Immunohistochemistry}

Four adult male Wistar rats were used in this portion of the study. Rats were deeply anesthetized and perfused through the left cardiac ventricle with a solution of $4 \%$ paraformaldehyde and $0.1 \%$ glutaraldehyde in $0.1 \mathrm{M}$ phosphate buffer $(\mathrm{pH}$ 7.4). The brains were removed and sectioned coronally at $100 \mu \mathrm{m}$ using a vibrating microtome. Sections were washed 30 times for $5 \mathrm{~min}$ each with phosphate-buffered saline (PBS) and incubated overnight with an affinity-purified mouse monoclonal antibody to Alox15 (Abcam, Cambridge, UK), diluted 1:50 in PBS. Sections were incubated for $1 \mathrm{~h}$ in a 1:100 dilution of biotinylated horse anti-mouse IgG (Vector, Burlingame, $\mathrm{CA})$, reacted for $1 \mathrm{~h}$ with avidin-biotinylated horseradish peroxidase complex, and visualized by treatment for $22 \mathrm{~min}$ in $0.05 \%$ 3,3-diaminobenzidine tetrahydrochloride solution in Tris buffer containing $0.05 \%$ hydrogen peroxide. Some sections were mounted on glass slides and counterstained with methyl green and visualized with a light microscope. The remaining sections were processed for electron microscopy.

\section{Electron Microscopy}

Electron microscopy was carried out by subdissecting immunostained sections of the prefrontal cortex into smaller rectangular portions $(1.0 \times 1.5 \mathrm{~mm})$. Samples were osmicated for $1 \mathrm{~h}$ in osmium tetroxide $\left(\mathrm{OsO}_{4}\right)$, washed in distilled water for $20 \mathrm{~min}$, then dehydrated in an ascending series of ethanol and acetone as follows: $25 \%$ ethanol, $3 \mathrm{~min}$; $50 \%$ ethanol, $5 \mathrm{~min} ; 75 \%$ ethanol, $5 \mathrm{~min}$; 95\% ethanol, $5 \mathrm{~min} ; 100 \%$ ethanol, $5 \mathrm{~min} ; 100 \%$ acetone, $5 \mathrm{~min} \times 2$, then embedded in Araldite. Thin sections were obtained from the first $5 \mu \mathrm{m}$ of the sections, mounted on copper grids coated with Formvar, and stained with lead citrate. They were viewed using a JEOL 1010 EX electron microscope.

\section{Liquid Chromatography Mass Spectrometry}

Six adult male Wistar rats were used per group (vehicle control and Alox15 inhibitor) in the first portion of this study. Rats were stereotaxically injected with $5 \mu \mathrm{l}$ of either vehicle control (DMSO) or Alox15 inhibitor in DMSO $(40 \mathrm{mM})$ bilaterally at a rate of $5 \mathrm{~min}$ per injection as described above. After a 1-day time point, rats were deeply anesthetized with the ketamine/ xylazine cocktail and sacrificed by decapitation. The prefrontal cortex of these rats was removed and snap frozen in liquid nitrogen.

Six adult male Wistar rats were used per group (saline, Alox15 scrambled sense, and Alox15 antisense) in the second portion of this study. Rats were stereotaxically injected with either scrambled sense oligonucleotide, Alox15 antisense oligonucleotide, or saline bilaterally at a rate of $5 \mathrm{~min}$ per injection as described above. The prefrontal cortex was removed and snap frozen in liquid nitrogen.

Tissues were homogenized in $750 \mu \mathrm{l}$ of Folch solution (2:1 v/v chloroform/methanol) using a Tissue Tearor ${ }^{\mathrm{TM}}$ (Biospec, USA). Samples were then sonicated for $30 \mathrm{~min}$ at $4{ }^{\circ} \mathrm{C}$. A total of $200 \mu \mathrm{l}$ of $0.88 \% \mathrm{KCl}$ was added to each sample. Samples were vortexed for $1 \mathrm{~min}$, then centrifuged at $9000 \mathrm{~g}$ for $2 \mathrm{~min}$, and the organic portions collected and vacuum-dried (Thermo Savant SpeedVac, USA). Lipids were then resuspended in $200 \mu \mathrm{l}$ of $100 \%$ acetonitrile and transferred to an amber glass vial for LC/MS analysis.

LC/MS assay was carried out using a Shimadzu LC system equipped with a binary gradient pump, auto-sampler, column oven, and diode array detector, coupled with a Shimadzu LCMS 8060 triple quadrupole mass spectrometer (Kyoto, Japan). Gradient elution involved a mobile phase consisting of (A) $0.1 \%$ formic acid in water and (B) $0.1 \%$ formic acid in acetonitrile. The initial condition was set at $5 \%$ of (B), gradient up to $100 \%$ in $10 \mathrm{~min}$ and returning to initial condition for $5 \mathrm{~min}$. Oven temperature was set at $40{ }^{\circ} \mathrm{C}$ and flow rate was set at $250 \mu \mathrm{l} / \mathrm{min}$. For all experiments, $2 \mu \mathrm{l}$ of samples was injected. The column used for the separation was a reversedphase Zorbax SB18, $50 \times 2.0 \mathrm{~mm}, 3.5 \mu \mathrm{m}$ (Agilent Technologies, USA). The ESI/MS was acquired in the positive and negative ion mode. Product ions of $\mathrm{m} / \mathrm{z}$ range from 100 to 800 were collected. The drying gas and nebulizer nitrogen gas flow rates were $10 \mathrm{l} / \mathrm{min}$ and $1.5 \mathrm{l} / \mathrm{min}$ respectively. The DL temperature was ${ }^{\circ} \mathrm{C}$ and $\mathrm{BH}$ temperature was $400{ }^{\circ} \mathrm{C}$. The LC/MS data were peak-detected and noise reduced, such that only true analytical peaks were further processed. A list of the intensities of the peaks detected was then generated manually and tabulated into Microsoft Excel for each sample run, using the retention tine (RT) and $\mathrm{m} / \mathrm{z}$ data pairs as the identifier for each peak. The ion intensities for each peak detected were normalized within each sample, to the sum of the peak intensities in that sample. Differences in the amount of lipid species present were normalized to total amount of lipids in each sample and analyzed using one-way ANOVA or twotailed unpaired Student's $t$ test. $P<0.05$ was considered significant. 


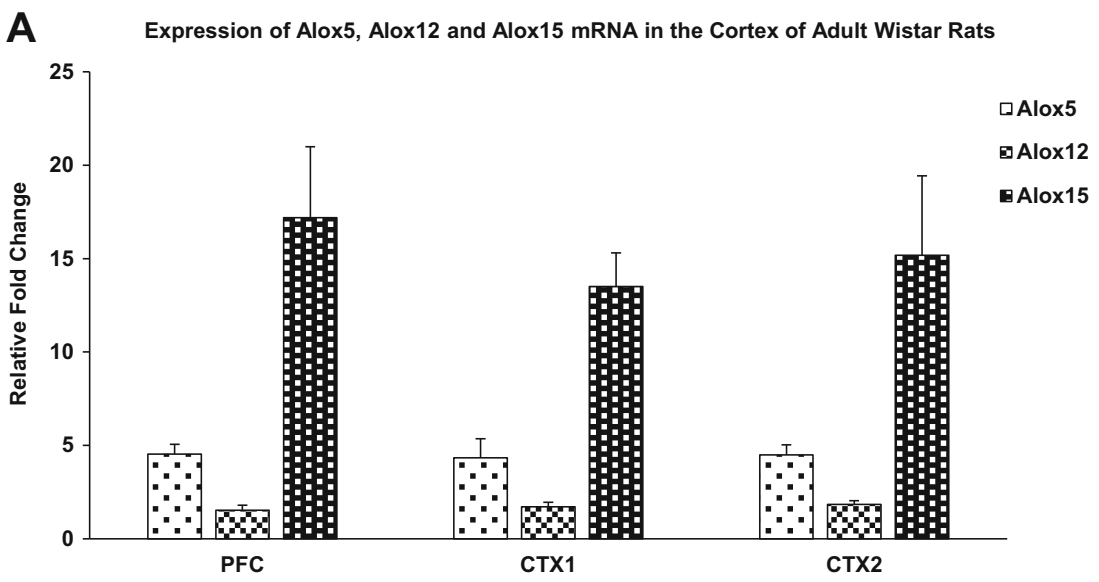

B Expression of 15 Lipoxygenase 1 (Alox15) mRNA in the CNS of Adult Wistar Rats

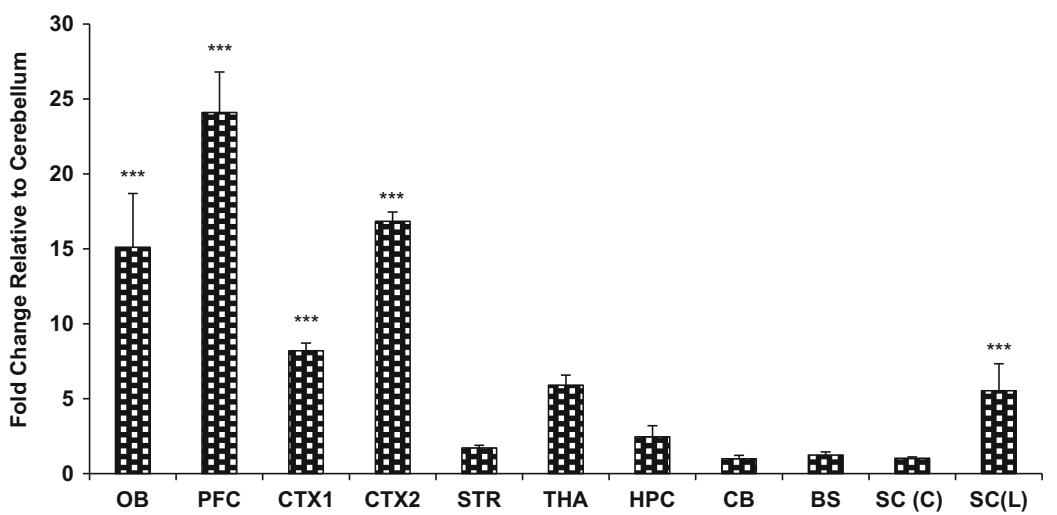

Fig. 1 a Differential expression of Alox5, Alox12, and Alox15 mRNA in the cortex of adult Wistar rats. Anatomically, cortex 1 contains the primary and secondary motor cortex and the primary somatosensory cortex, whereas cortex 2 includes the parietal association cortex and secondary auditory cortex. b Differential expression of Alox 15 mRNA in the CNS of adult Wistar rats in the olfactory bulb, prefrontal cortex, cortex, striatum, hippocampus, thalamus, cerebellum, brainstem, and spinal cord. Asterisks indicate significant differences relative to cerebellum at $* P<0.05$, $* * P<0.01$, $* * * P<0.001$, one-way ANOVA with Bonferroni post hoc test. Abbreviations: $O B$ olfactory bulb, $P F C$ prefrontal cortex, CTX1 cortex 1, CTX2 cortex 2, STR striatum, HC hippocampus, $C X$ cerebral cortex, $S E$ septum, $S T$ striatum, $H C$ hippocampus, $T H$ thalamus, $C B$ cerebellum, $B S$ brainstem, $S C(C)$ cervical region of spinal cord, $S C(L)$ lumbar region of spinal cord

\section{In Vivo Electrophysiology}

Six adult male Wistar rats were used per treatment group (vehicle control, Alox15 inhibitor, scrambled sense oligonucleotide, and Alox15 antisense oligonucleotide) in this portion of the study. Rats underwent in vivo electrophysiology testing 1 day after intracortical injection (for inhibitor studies) and 4 days after intracortical injection (for antisense studies). The in vivo electrophysiology procedure was conducted as described previously [34]. Rats were anesthetized with urethane (Sigma-Aldrich) and mounted on a stereotaxic frame (Stoelting). Urethane was freshly prepared in sterile isotonic saline $(0.9 \%$ sodium chloride solution) before use, at a concentration of $1 \mathrm{~g} / \mathrm{kg}$ body weight. Body temperature was maintained at $37{ }^{\circ} \mathrm{C}$ by a homeothermic blanket. A midline incision was made on the scalp and small craniotomies performed using a burr over the sites of insertion of the electrodes. A bipolar nichrome wire stimulating electrode was placed in the CA1/subicular region of the temporal hippocampus (6.3 $\mathrm{mm}$ posterior and $5.5 \mathrm{~mm}$ lateral to the bregma). A monopolar stainless steel recording electrode (SNE-300, David Kopf Instruments, Tujunga, USA) with a recording tip of diameter $100 \mu \mathrm{m}$ and length $250 \mu \mathrm{m}$ was placed in the prelimbic area of the prefrontal cortex $(3.3 \mathrm{~mm}$ anterior and $0.9 \mathrm{~mm}$ lateral to the bregma). Coordinates were determined by reference to the atlas of Paxinos and Watson 1998 [31].

Stimulation of the CA1/subicular region of the hippocampus resulted in characteristic monosynaptic negative-going field potential recorded from the prefrontal cortex, with a latency of 18-24 ms. The depths of the stimulating and recording electrodes $(5.8-7.2 \mathrm{~mm}$ and $3.2-4.7 \mathrm{~mm}$ from the skull surface, respectively) 
A OB PFC CTX1 CTX2 STR TH HC CB BS SC(C) SC(L)

$75 \mathrm{kDa}$

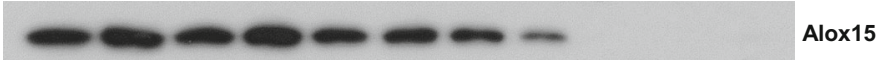

$42 \mathrm{kDa}$

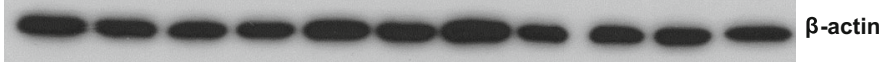

B Differential Expression of 15 Lipoxygenase 1 Protein in the CNS of Adult Wistar Rats

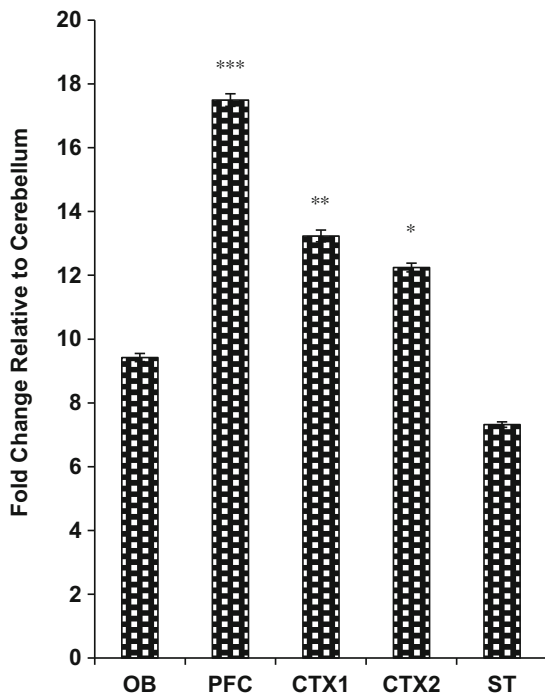

Fig. 2 a Western blot of differential expression of Alox 15 protein expression in the CNS of adult Wistar rats in the olfactory bulb, prefrontal cortex, cortex, striatum, hippocampus, thalamus, cerebellum, brainstem, and spinal cord. b Densitometric analyzes differential expression of Alox15 protein expression in the CNS of adult Wistar rats. Asterisks indicate significant differences relative to cerebellum at

were adjusted to maximize the amplitude of negativegoing peak of the evoked response. During the initial localization of the response, stimulation at varying intensities (between 200 and $350 \mu \mathrm{A}$ ) was delivered once every $15 \mathrm{~s}$. Once an appropriate response was established, a period of $10 \mathrm{~min}$ was given to allow for response stabilization. The stimulus intensity required to evoke a response that was $70 \%$ of the maximal response was determined via rendering of an input/output curve (IOC) and used during the protocol. The stimulation protocol used for the experiment is as follows: baseline recording was performed once every $30 \mathrm{~s}$ for $30 \mathrm{~min}$ at the stimulus intensity determined by the IOC. Highfrequency stimulation (HFS) was then delivered (50 pulses at $250 \mathrm{~Hz}, 4 \mathrm{~ms}$ interval between pulses). This sequence was repeated 10 times. After HFS, baseline stimulation was resumed, and recording was continued for at least $90 \mathrm{~min}$. Five-minute averages of the amplitude were calculated for further analysis, and the average field excitatory post-synaptic potentials (fEPSP) expressed as mean percentage \pm SEM normalized to baseline for each experiment. Differences between
fEPSP (\%) recorded for each treatment group were analyzed using repeated measures two-way ANOVA. $P<0.05$ was considered significant.

\section{Rewarded Alternation in a T-Maze}

Six adult male Wistar rats were used per group (vehicle control, Alox15 inhibitor, scrambled sense oligonucleotide, and Alox15 antisense oligonucleotide) in this portion of the study. The T-maze rewarded alternation testing procedure was conducted as previously described [35]. Rats were habituated for 5 days and trained for a further 5 days to alternate in the maze in order to obtain a food reward. On day 11, rats underwent intracortical injection of vehicle control, Alox15 inhibitor, scrambled sense oligonucleotide, or Alox15 antisense oligonucleotide in a blinded manner. They were subsequently tested on the T-maze. Differences in the number of correct options (entry into previously unentered arm) were analyzed using the two-tailed unpaired Student's $t$ test. $P<0.05$ was considered significant. 

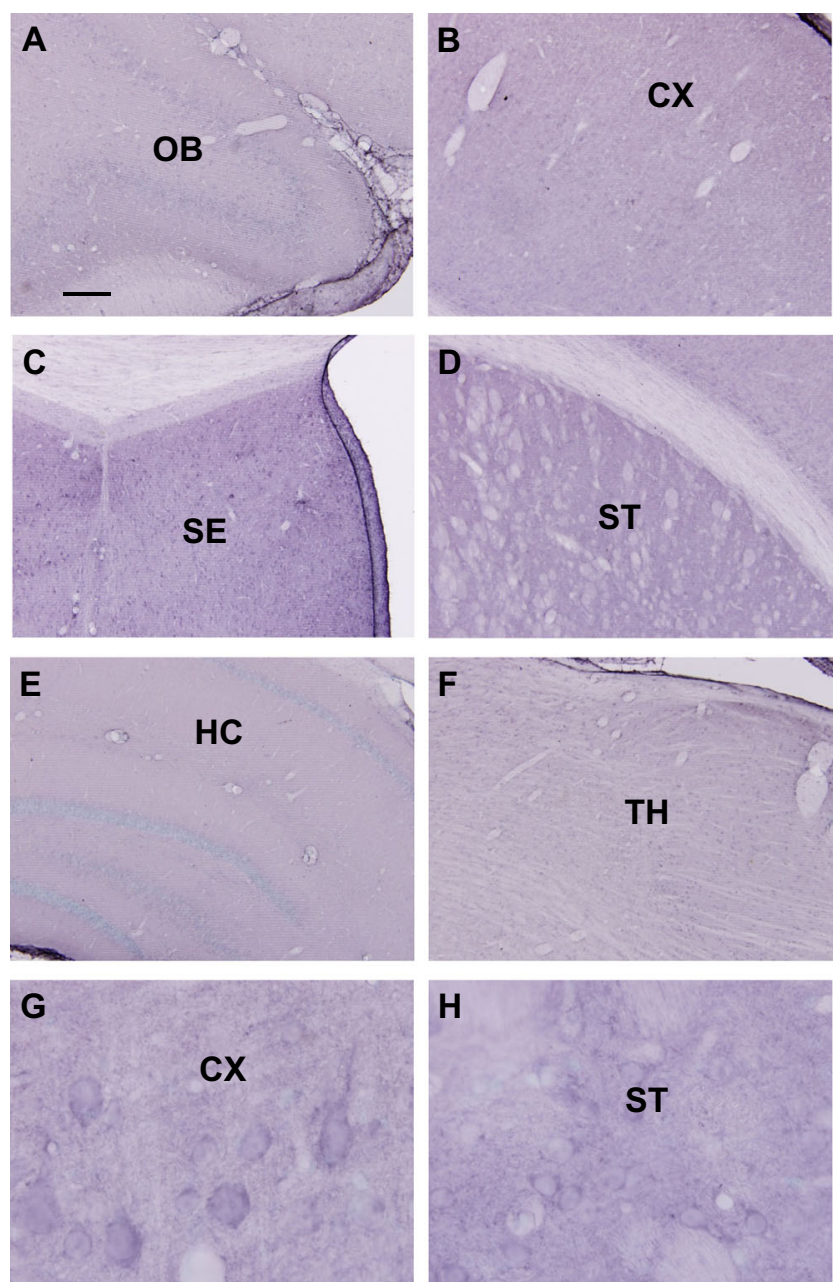

Fig. 3 Immunohistochemical labeling of Alox 5 in the forebrain. Moderately dense staining is observed in the olfactory bulb (a), cerebral cortex, including the prefrontal cortex (b), septum (c), striatum (d), while light staining is observed in the hippocampus (e), thalamus (f), and hypothalamus. Staining is mostly observed as punctuate profiles in the neuropil in these regions, and cell bodies were mostly unlabeled $(\mathbf{g}, \mathbf{h})$. Abbreviations: $O B$ olfactory bulb, $C X$ cerebral cortex, $S E$ septum, $S T$ striatum, $H C$ hippocampus, $T H$ thalamus. Scale: $\mathbf{a}-\mathbf{f}=200 \mu \mathrm{m} . \mathbf{g}$, $\mathbf{h}=20 \mu \mathrm{m}$

\section{Results}

\section{Real-Time Reverse Transcriptase Polymerase Chain Reaction}

Real-time RT-PCR results showed that Alox15 is the highestexpressing isoform in the rat cortex, compared to Alox 5 and Alox12. Alox15 mRNA expression was higher than those of Alox 5 and Alox 12 in the prefrontal cortex, the primary and secondary motor cortex, the primary somatosensory cortex, the parietal association cortex, and secondary auditory cortex (Fig. 1a).

After normalization to the endogenous control, $\beta$-actin, the relative mRNA expression of Alox15 was determined in each brain region relative to the area with lowest expression, the
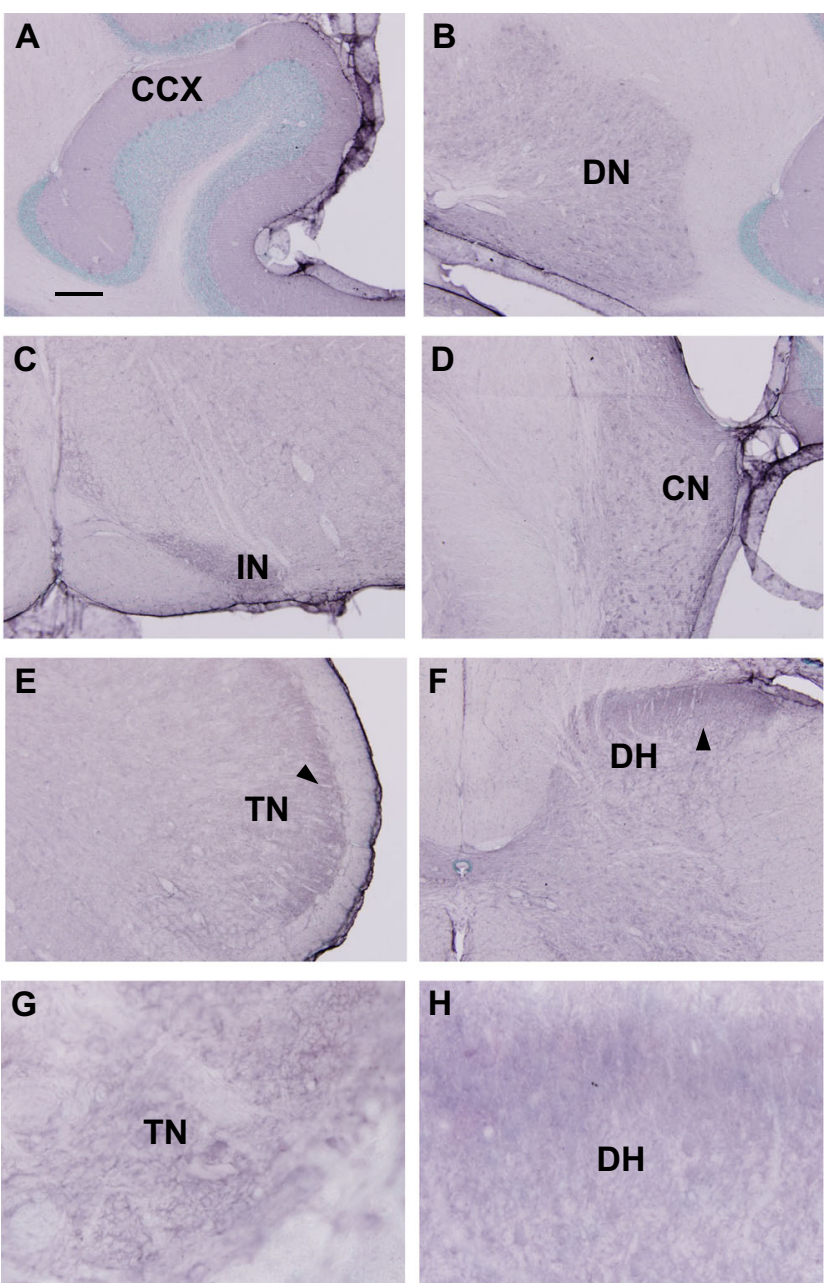

Fig. 4 Immunohistochemical labeling of Alox 5 in the hindbrain and spinal cord. The cerebellum including the cerebellar cortex (a) and deep cerebellar nuclei (b) were moderately labeled. Most parts of the brainstem are lightly labeled, except for the inferior olivary nucleus (c), dorsal and ventral cochlear nuclei (d), and superficial portion of the spinal trigeminal nucleus (e). The spinal cord is also lightly labeled, except the substantia gelatinosa, in the superficial part of the dorsal horn (f). Staining is mostly observed as punctuate profiles in the neuropil in these regions, and cell bodies were mostly unlabeled $(\mathbf{g}, \mathbf{h})$. Abbreviations: $C C X$ cerebellar cortex, $D N$ dentate nucleus, $I N$ inferior olivary nucleus, $C N$ cochlear nucleus, $T N$ spinal trigeminal nucleus, $D H$ dorsal horn of spinal cord (lumbar region). Arrowheads indicate immunoreaction product in superior portion of spinal trigeminal nucleus and dorsal horn. Scale: a$\mathbf{f}=200 \mu \mathrm{m} . \mathbf{g}, \mathbf{h}=20 \mu \mathrm{m}$

cerebellum. Real-time RT-PCR results indicate that the prefrontal cortex exhibits the highest mRNA expression level with approximately 25 -fold greater expression than the cerebellum, followed by the parietal association cortex and secondary auditory cortex with over 15 -fold greater expression than the cerebellum, olfactory bulb with approximately 15fold greater expression than the cerebellum, motor and somatosensory cortices, and the hippocampus. Higher Alox15 mRNA levels are expressed across the forebrain regions as compared to the hindbrain and the spinal cord (Fig. 1b). 

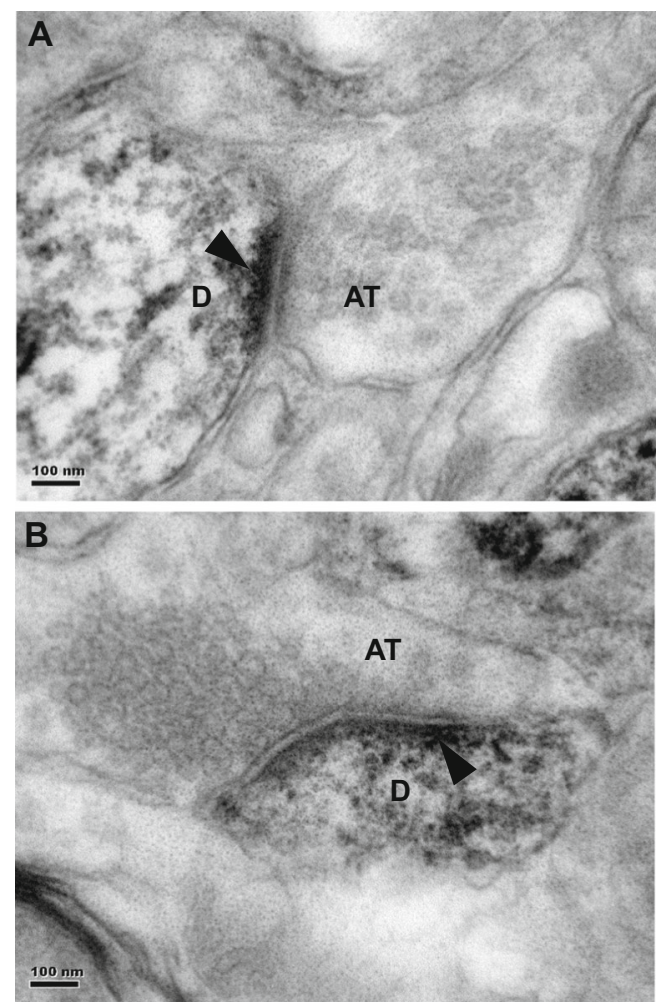

Fig. 5 Electron microscopy of immunostained sections of the prefrontal cortex showed dense staining of the neuropil. Label was observed in dendrites or dendritic spines (a, b). Arrowheads indicate immunoreaction product. Scale $=100 \mathrm{~nm}$. Abbreviations: $A T$ axon terminal, $D$ dendrite

\section{Western Blot Analysis of Alox15 Protein Expression in the Brain}

The Alox15 antibody detected a single $75 \mathrm{kDa}$ band in the adult rat brain (Fig. 2a). The $75 \mathrm{kDa}$ band size is consistent with the predicted $75 \mathrm{kDa}$ Alox 15 protein size [6], and to date, no significant glycosylation of the enzyme has been identified nor are there any indications of myristoylation or isoprenylation [36, 37]. Quantification of protein was determined by densitometric analysis of Alox 15 bands normalized to that of $\beta$-actin.

To maintain consistency in comparison across real-time RT-PCR and Western blot, fold change levels were compared relative to the cerebellum. The prefrontal cortex was found to have the highest Alox15 protein expression with levels approximately 18 -fold more than that of the cerebellum, followed by cortex 1 (13-fold), cortex 2 (12-fold), hippocampus (10fold), and olfactory bulb (9-fold). The striatum and thalamus display relatively lower levels of protein expression while the hindbrain regions of cerebellum and brainstem and the spinal cord have low and insignificant levels of Alox 15 expression. Results from the quantitative densitometric analysis of the Western blots are consistent with those of real-time RT-PCR. Overall, the prefrontal cortex expresses the highest Alox15
mRNA and protein expression levels relative to the cerebellum, followed by the cerebral cortical areas (Fig. 2b).

\section{Immunohistochemistry}

Moderately dense staining was observed in the olfactory bulb (Fig. 3a), cerebral cortex, including the prefrontal cortex (Fig. 3b), septum (Fig. 3c), striatum (Fig. 3d), while light staining was observed in the hippocampus (Fig. 3e), thalamus (Fig. 3f), and hypothalamus. Staining was mostly observed as punctuate profiles in the neuropil in these regions, and cell bodies were mostly unlabeled (Fig. 3g, h).

The cerebellum including the cerebellar cortex (Fig. 4a) and deep cerebellar nuclei (Fig. 4b) was moderately labeled. Most parts of the brainstem were lightly labeled, except for the inferior olivary nucleus (Fig. 4c), the dorsal and ventral cochlear nuclei (Fig. 4d), and the superficial portion of the spinal trigeminal nucleus (Fig. 4e). The spinal cord was also lightly labeled, except the substantia gelatinosa, in the superficial part of the dorsal horn (Fig. 4f). Staining was mostly observed as punctuate profiles in the neuropil in these regions, and cell bodies were mostly unlabeled (Fig. $4 \mathrm{~g}, \mathrm{~h}$ ).

\section{Electron Microscopy}

Electron microscopy of immunostained sections of the prefrontal cortex showed dense staining of the neuropil. Label was observed in dendrites or dendritic spines (Fig. 5a, b).

\section{Western Blot Analysis to Confirm Alox15 Knockdown with Antisense Oligonucleotide}

The Alox15 antibody detected a single $75 \mathrm{kDa}$ band in the adult rat brain (Fig. 6a), consistent with the predicted size of Alox 15 protein. Analyses of normalized density of Alox 15 bands to $\beta$-actin showed a significant $82 \%$ decrease $(P<0.05)$ in Alox 15 protein levels in antisense-injected rats, indicating effective knockdown by Alox 15 antisense oligonucleotide.

\section{Liquid Chromatography Mass Spectrometry}

LCMS analysis shows a statistically significant decrease in resolvin D1 levels $(P<0.05)$ (Fig. 6b) after intracortical injection of Alox15 inhibitor in the prefrontal cortex of the rat brain.

LCMS analysis shows a statistically significant decrease in resolvin D1 levels $(P<0.01)$ (Fig. $6 \mathrm{c})$ after intracortical injection of Alox 15 antisense in the prefrontal cortex of the rat brain compared to saline and scrambled sense injected rats. 
Fig. 6 a Western blot of effect of Alox15 oligonucleotide treatment on Alox 15 protein expression in the rat prefrontal cortex. b LCMS analysis of effect of Alox15 inhibitor treatment on resolvin D1 levels in the rat prefrontal cortex. c LCMS analysis of effect of Alox15 oligonucleotide treatment on resolvin D1 levels in the rat prefrontal cortex. Asterisk (*) indicate significant differences at $P<0.05$, two-tailed Student's $t$ test. Asterisks (**) indicate significant differences at $P<0.01$, one-way ANOVA with bonferroni post hoc test

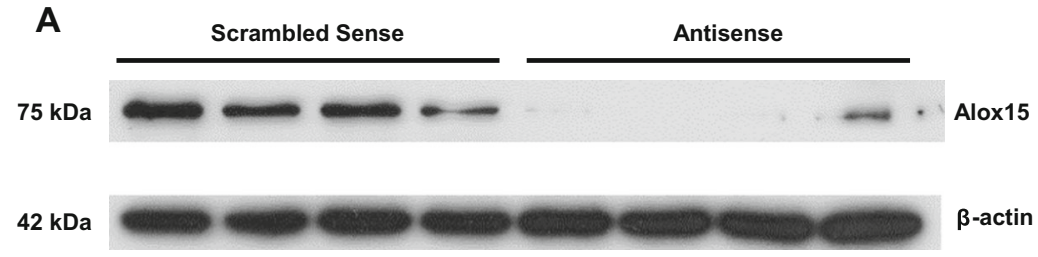

B Resolvin D1 Levels Detected by LCMS in the PFC of Rat Brain

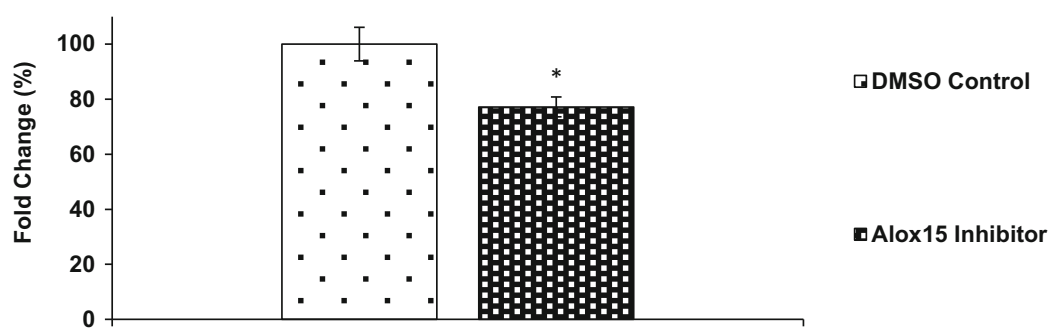

C Resolvin D1 Levels Detected by LCMS in the PFC of Rat Brain

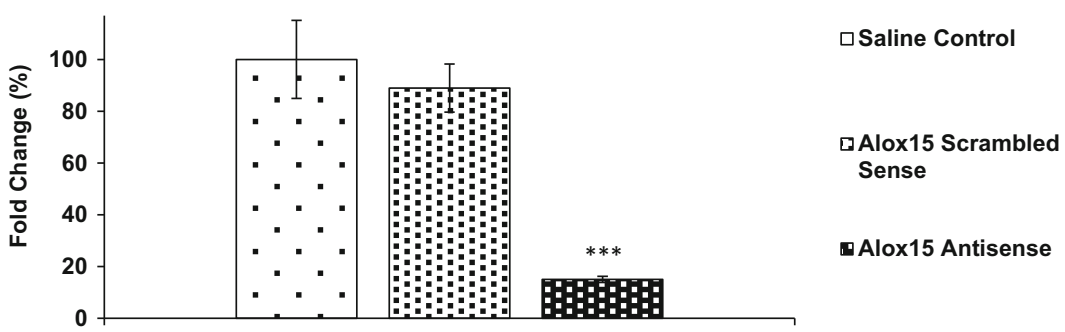

\section{In Vivo Electrophysiology}

The effects of hippocampal stimulation on LTP induction in the hippocampo-prefrontal cortex pathway for rats treated with Alox15 inhibitor and DMSO vehicle control were evaluated by in vivo electrophysiology (Fig. 7a). Repeated measures two-way ANOVA indicated that HFS did induce LTP in control groups $F(24,120)=12.913, P<0.001$ and also indicated that the treatment (Alox15 inhibitor) exerted a significant effect on fEPSPs $F(1,10)=34.759, P<0.001$. Further, two-tailed Student's $t$ tests carried out to compare between the treatment groups showed no significant difference between fEPSPs of vehicle control and Alox15-injected rats before HFS, but confirmed a significant $(P<0.001)$ difference after HFS, sustained for $90 \mathrm{~min}$ post-HFS (Fig. 7b). This indicates that intracortical injection of Alox 15 inhibitor prevented induction of LTP along the hippocampo-prefrontal cortex pathway.

These results were confirmed with intracortical injection of Alox15 antisense oligonucleotides and scrambled sense control (Fig. 8a.) Repeated measures two-way ANOVA indicated that HFS did induce LTP in control groups $F(24,120)=26.315, P<0.001$ and also indicated that the treatment (Alox15 antisense) exerted a significant effect on fEPSP $F(1,10)=156.178$,
$P<0.001$. Further, two-tailed Student's $t$ tests carried out to compare between the treatment groups showed no significant difference between fEPSPs of scramble sense and Alox 15 antisense rats before HFS, but confirmed a significant $(P<0.001)$ difference after HFS, sustained for $90 \mathrm{~min}$ post-HFS (Fig. 8b). This confirms that genetic knockdown of Alox15 prevented induction of LTP along the hippocampo-prefrontal cortex pathway.

\section{Rewarded Alternation in T-Maze}

Performance of rats in the rewarded alternation task in the T-maze was measured by the total number of correct responses (entry into previously unentered arm) made by a rat during the 5 training days and 3 testing days. Rats in the Alox15 and vehicle control groups performed equally well on training days 1-5. On testing day 1 (1 day after intracortical injection), rats injected with Alox15 inhibitor made significantly $(P<0.001)$ more errors than vehicle-injected controls. On testing days 2 and 3, performance of inhibitor-injected rats recovered to the same level as vehicle-injected controls (Fig. 9a).

Similarly, rats in the Alox15 antisense and scrambled sense control groups performed equally well on training 
Fig. 7 a Effects of hippocampal stimulation on fEPSP in prefrontal cortex. Data points represent mean fEPSP over the preceding 5 min. Error bars represent SEM. $n=6$ for all treatment groups. Alox15 inhibitor treatment has a significant effect on fEPSP. $F(1,10)=34.759, P<0.001$. Repeated measures two-way ANOVA. b DMSO control vs Alox15 inhibitor. Columns represent mean normalized fEPSP over the preceding $30 \mathrm{~min}$. Asterisks (***) indicate significant differences at $P<0.05$, two-tailed Student's $t$ test

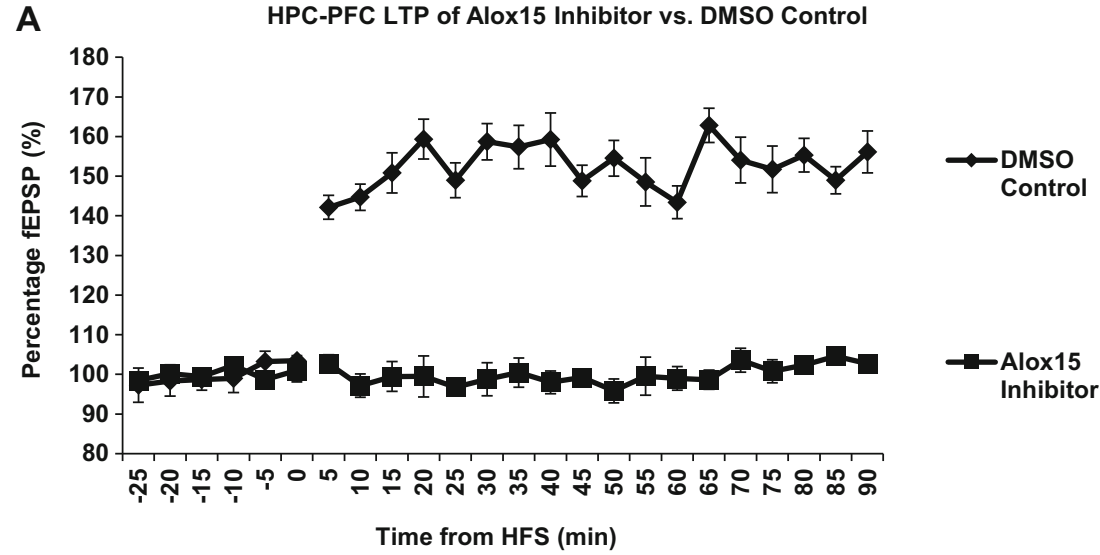

B Mean Normalised Percentage fEPSP of HPC-PFC LTP of Alox15 Inhibitor vs. DMSO Control

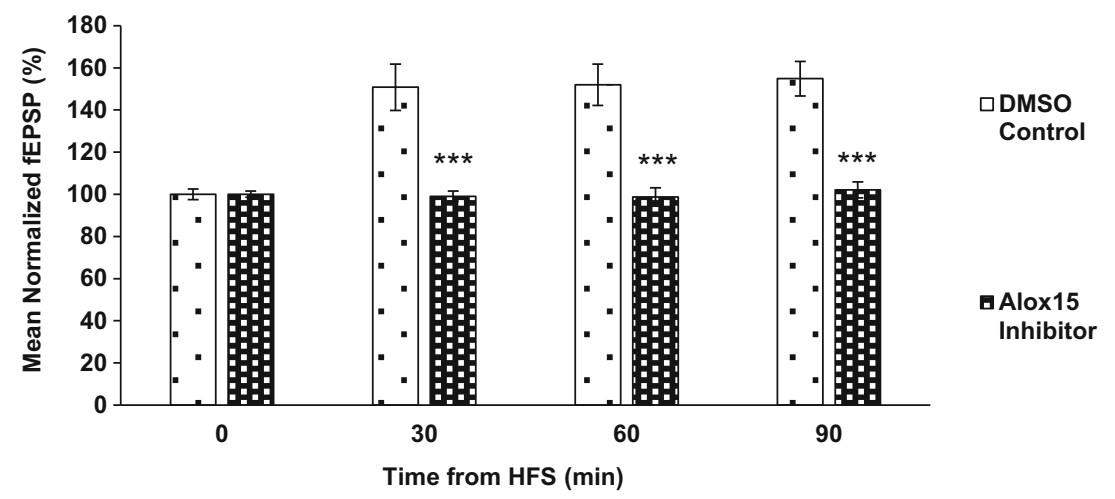

days 1-5, while rats injected with Alox 15 antisense oligonucleotide made significantly $(P<0.001)$ more errors than scrambled sense injected controls on testing days 2 and 3, which corresponds with the time taken for the antisense oligonucleotide to knock down protein expression (Fig. 9b). This confirms that the Alox15 enzyme in the prefrontal cortex is essential for spatial working memory.

\section{Discussion}

The expression levels of reticulocyte-type Alox15 across the CNS were studied via real-time RT-PCR and Western blot. Real-time RT-PCR results indicate that Alox15 mRNA is present across all 11 different brain regions studied, with the olfactory bulb, prefrontal cortex, cerebral cortices, and the hippocampal regions displaying significant levels of expression while the hindbrain regions such as the brain stem and the spinal cord express nonsignificant low mRNA levels. Comparison with other lipoxygenases shows that Alox15 is the highestexpressing isoform in the rat cortex, compared to Alox 5 and Alox12. Protein expression levels exhibited by
Western blot were largely consistent with the results of real-time RT-PCR. The prefrontal cortex displays the highest mRNA and protein levels relative to the cerebellum, but various parts of the hindbrain and the spinal cord display almost non-quantifiable protein levels of Alox 15 relative to the cerebellum in Western blot. Tissue localization via immunohistochemistry supported the results of real-time RT-PCR and Western blot. The olfactory bulb, septum, cerebral cortex, striatum, and cerebellar cortex showed moderate Alox 15 staining. The distinct patterns of relative distribution and localization as elucidated by this investigation may provide insight into the roles of Alox15 in synaptic plasticity and neurodegenerative diseases. The high level of expression of Alox15 in the prefrontal cortex suggests that the enzyme may play an important role in functions such as synaptic plasticity and learning and memory. The brainstem and spinal cord showed light staining, except the inferior olivary nucleus, and some of the sensory nuclei such as the dorsal and ventral cochlear nuclei, the spinal trigeminal nucleus, and the dorsal horn of the spinal cord. In both the spinal trigeminal nucleus and the dorsal horn of the spinal cord, staining is found in the entry zone of primary afferents, i.e., the substantia gelatinosa, which is consistent with a 
Fig. 8 a Effects of hippocampal stimulation on fEPSP in prefrontal cortex. Data points represent mean fEPSP over the preceding 5 min. Error bars represent SEM. $n=6$ for all treatment groups. Alox15 oligonucleotide treatment has a significant effect on fEPSP. $F$ $(1,10)=156.178, P<0.001$. Repeated measures two-way ANOVA. b Scrambled sense control vs Alox15 antisense oligonucleotide. Columns represent mean normalized fEPSP over the preceding $30 \mathrm{~min}$. Asterisks (***) indicate significant differences at $P<0.05$, two-tailed Student's $t$ test
A HPC-PFC LTP of Alox15 Antisense vs. Scrambled Sense Oligonucleotide

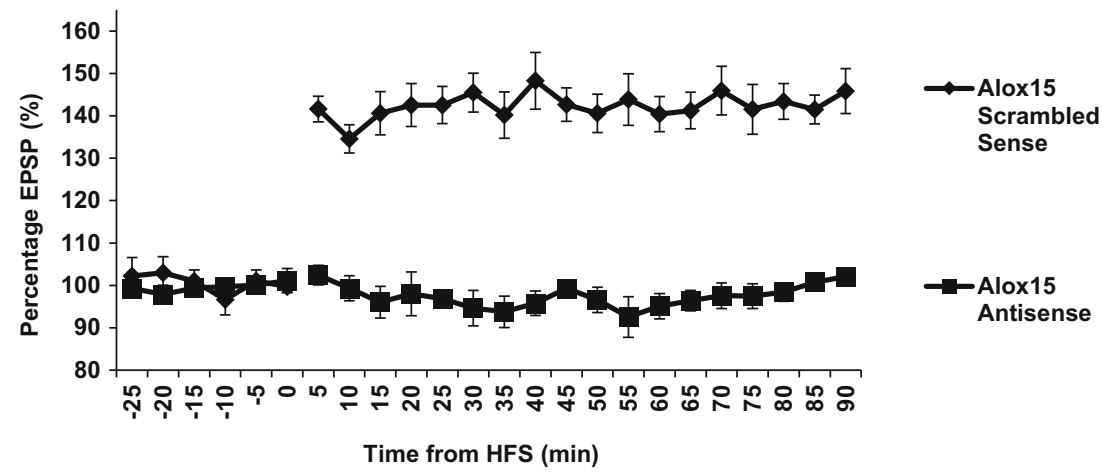

B

Mean Normalised Percentage fEPSP of HPC-PFC LTP of Alox15 Antisense vs. Scrambled Sense Oligonucleotide

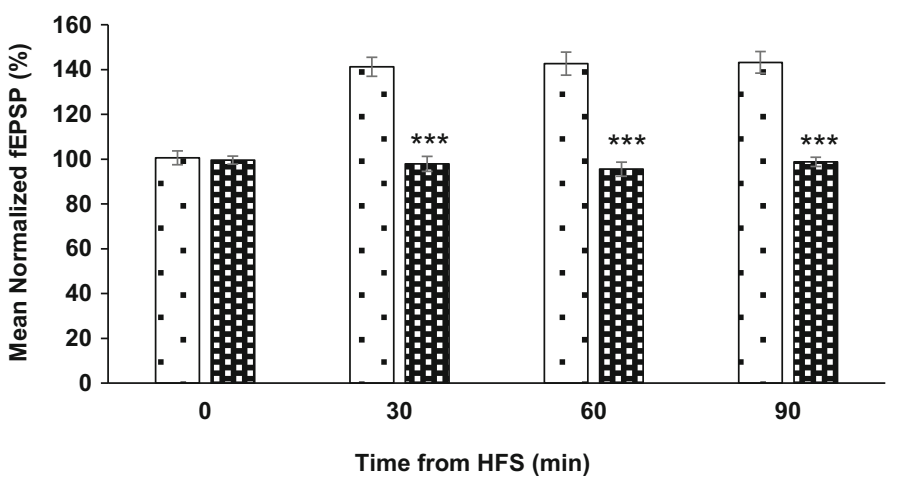

$\square$ Alox15

Scrambled Sense

Alox15

Antisense role of Alox15 product, resolvin D1 in antinociception [38-40].

We next studied the functional role of Alox15 in prefrontal cortex, a region that showed high level of gene expression by RT-PCR, Western blot, and immunohistochemistry. In this study, we showed that Alox15 inhibition/knockdown resulted in a decrease in resolvin D1 levels. Resolvin D1 has been shown to be a potent inhibitor for inflammatory pain [38] and also blocks TNF $\alpha$-induced IL-1 $\beta$ transcripts and regulates PMN infiltration in brain [11]. In addition, resolvin D1 has been shown to alter synaptic plasticity in the mouse spinal cord [38]. Given the potential role of RvD1 in synaptic plasticity, the effects of Alox15 inhibition/knockdown on in the prefrontal cortex were investigated using LTP, a model of synaptic plasticity underlying learning. The prefrontal cortex and hippocampus are functionally related due to projections from the CA1 region of the hippocampus to the medial and orbital prefrontal cortex [41] - forming the hippocampoprefrontal cortex pathway, a possible pathway via which spatial information is integrated in cognitive functions and goal directed motor behavior $[42,43]$. Induction of LTP in the hippocampo-prefrontal cortex pathway is characterized by an increase in the amplitude of the evoked excitatory postsynaptic field potential (fEPSP) recorded in the prefrontal cortex upon administration of a HFS to the hippocampus [44]. We observed that injection of an inhibitor or antisense oligonucleotide to Alox 15 successfully prevented LTP induction in the hippocampo-prefrontal cortex pathway. The antisense knockdown of Alox 15 was further corroborated by Western blot analysis showing a significant decrease in Alox15 protein expression in the prefrontal cortex after injection.

In view of the abovementioned effects of Alox 15 inhibition/knockdown on LTP in the hippocampo-prefrontal cortex pathway, we postulated that Alox15 could be essential for spatial working memory, which is dependent on the pathway. Spatial working memory acts to maintain memory of the spatial information of an object, stimulus association, or location within a specific test session but not between sessions [45]. Rodents have a natural tendency to alternate their choice of goal arm in a T-maze task, which reflects an adaptation to efficiently locate resources such as food, water, and shelter in their natural environment [46] and provision of a food reward increases the motivation to perform the task [47]. Rats that received Alox15 inhibitor or Alox15 antisense oligonucleotide injection in the prefrontal cortex showed poor performance in the rewarded alternation in T-maze task compared to those injected with controls. The role of the hippocampo- 
Fig. 9 a Percentage correct responses made during T-maze procedure, DMSO control vs. Alox15 inhibitor. b Percentage correct responses made during Tmaze procedure, Alox15 antisense oligonucleotide vs scrambled sense control. Asterisks $(* * *)$ indicate significant differences at $P<0.05$, two-tailed Student's $t$ test
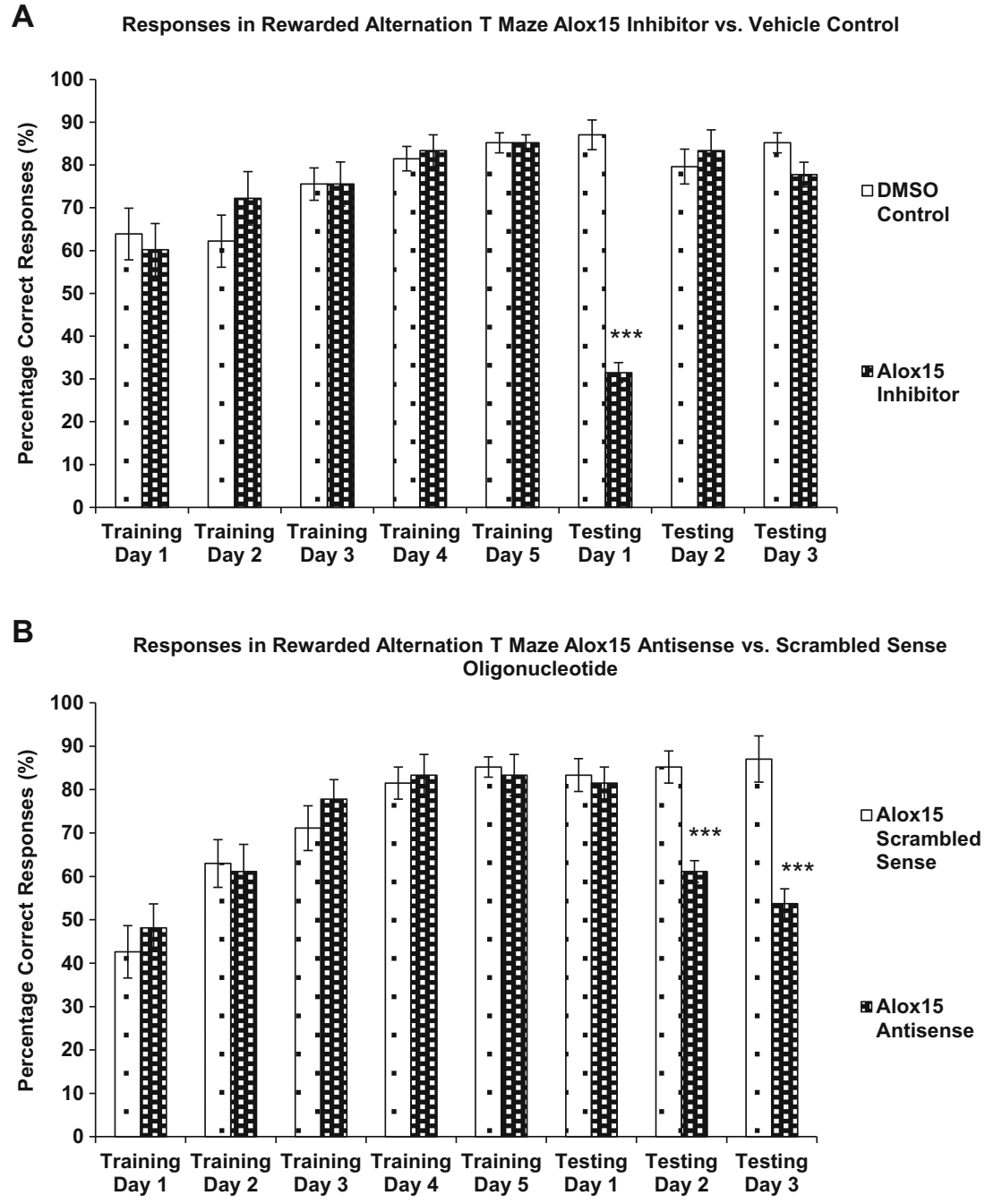

prefrontal cortex pathway has been observed previously by examining performance in a delayed radial maze task, after unilateral lesion of the ventral subiculum in combination with a contralateral lesion of the prefrontal cortex. These combined lesions produced a disruption of foraging only during the test phase of this delayed win-shift task, similar to that described after bilateral inactivation of the prelimbic area [48], suggesting that transmission of information between the hippocampus and the prefrontal cortex is required when task-specific shortterm memory is used to facilitate search behavior [42]. The present findings of an important role of Alox15 in prefrontal cortical function adds to our recent results that show Alox15 plays a role in supraspinal antinociception originating in the prefrontal cortex [12].

Electron microscopic analysis revealed immunolocalization of Alox15 at dendrites, which is consistent with a role in synaptic plasticity in the prefrontal cortex. NMDA receptors are important for induction of many forms of LTP including LTP in the hippocampo-prefrontal cortex pathway [49]. DHA, the major substrate of Alox15 in production of resolvin
D1, has been reported to increase expression of NMDA receptor subunits important for synaptic plasticity and memory $[50,51]$. Consistent with the role of PUFAs, including DHA, in promoting NMDA receptor subunit expression and inductions of LTP, dietary omega-3 deficiency reduces BDNF content and activation of NMDA receptors in the rat hippocampus [52]. In comparison, dietary enrichment with omega-3 PUFAs, including DHA, was also reported to reverse agerelated decreases in the GluR2 and NR2B glutamate receptor subunits in the rat forebrain [53].

Intrathecal RvD1 has been shown to block mechanical hyperalgesia and allodynia [54, 55]. The effect of RvD1 in inhibiting neuropathic pain points to a central mechanism involving changes in neuroplasticity. RvD1 could mediate its effects on neuroplasticity through binding with known RvD1 receptors formyl-peptide receptor 2 (FPR2) and G protein-coupled receptor 32 (GPR32) [56]. Although GPR32 is a pseudogene in rats, the binding of RvD1 to GPR32 has been documented in humans to attenuate inflammationinduced mechanical hypersensitivity and spinal 
TNF release $[55,57]$. Activation of the $G$ protein-coupled receptors FPR2 and GPR 32 by RvD1 in the central sensory pathway may alter synaptic transmission [54, 55], and one study has indicated transient receptor potential ion channel vanilloid 3 (TRPV3) as a molecular target for RvD1 [58].

In conclusion, the current findings indicate that Alox 15 processing of DHA contributes to production of resolvin D1 and LTP at hippocampo-prefrontal cortex synapses and associated spatial working memory performance. Our findings point to the role of anti-inflammatory molecules such as resolvin D1 in neuroplasticity and brain signaling, and possible disturbances in this system under conditions of neuroinflammatory brain disorders and chronic neurodegeneration.

Acknowledgements This work was supported by grants from the National Medical Research Council and National University Health System of Singapore.

\section{Compliance with Ethical Standards}

Conflict of Interest The authors declare that they have no conflict of interest.

Open Access This article is distributed under the terms of the Creative Commons Attribution 4.0 International License (http:// creativecommons.org/licenses/by/4.0/), which permits unrestricted use, distribution, and reproduction in any medium, provided you give appropriate credit to the original author(s) and the source, provide a link to the Creative Commons license, and indicate if changes were made.

\section{References}

1. Brash AR (1999) Lipoxygenases: occurrence, functions, catalysis, and acquisition of substrate. J Biol Chem 274(34):23679-23682

2. Boyington JC, Gaffney BJ, Amzel LM (1993) The threedimensional structure of an arachidonic acid 15-lipoxygenase. Science 260(5113):1482-1486

3. Rapoport SM, Schewe T (1986) The maturational breakdown of mitochondria in reticulocytes. Biochim Biophys Acta 864(3-4):471-495

4. Schewe T (2002) 15-lipoxygenase-1: a prooxidant enzyme. Biol Chem 383(3-4):365-374. doi:10.1515/BC.2002.041

5. Jiang WG, Watkins G, Douglas-Jones A, Mansel RE (2006) Reduction of isoforms of 15-lipoxygenase (15-LOX)-1 and 15LOX-2 in human breast cancer. Prostaglandins Leukot Essent Fat Acids 74(4):235-245. doi:10.1016/j.plefa.2006.01.009

6. Sigal E, Craik CS, Highland E, Grunberger D, Costello LL, Dixon RA, Nadel JA (1988) Molecular cloning and primary structure of human 15-lipoxygenase. Biochem Biophys Res Commun 157(2): 457-464

7. Brash AR, Boeglin WE, Chang MS (1997) Discovery of a second 15S-lipoxygenase in humans. Proc Natl Acad Sci U S A 94(12): 6148-6152

8. Ivanov I, Kuhn H, Heydeck D (2015) Structural and functional biology of arachidonic acid 15-lipoxygenase-1 (ALOX15). Gene 573(1):1-32. doi:10.1016/j.gene.2015.07.073
9. Kohli P, Levy BD (2009) Resolvins and protectins: mediating solutions to inflammation. Br J Pharmacol 158(4):960-971. doi:10.1111/j.1476-5381.2009.00290.x

10. Christie W (2014) Resolvins and Protectins. http://lipidlibrary.aocs. org/Primer/content.cfm?ItemNumber=39317. Accessed 25 July 2016

11. Hong S, Gronert K, Devchand PR, Moussignac RL, Serhan CN (2003) Novel docosatrienes and 17S-resolvins generated from docosahexaenoic acid in murine brain, human blood, and glial cells. Autacoids in anti-inflammation. J Biol Chem 278(17):1467714687. doi:10.1074/jbc.M300218200

12. Shalini SM, Herr DR, Ong WY (2016) The analgesic and anxiolytic effect of Souvenaid, a novel Nutraceutical, is mediated by Alox15 activity in the prefrontal cortex. Mol Neurobiol. doi:10.1007 /s12035-016-0138-2

13. Godsil BP, Kiss JP, Spedding M, Jay TM (2013) The hippocampalprefrontal pathway: the weak link in psychiatric disorders? Eur Neuropsychopharmacol 23(10):1165-1181. doi:10.1016/j. euroneuro.2012.10.018

14. Hashimoto M, Katakura M, Tanabe $\mathrm{Y}, \mathrm{Al}$ Mamun A, Inoue T, Hossain S, Arita M, Shido O (2015) N-3 fatty acids effectively improve the reference memory-related learning ability associated with increased brain docosahexaenoic acid-derived docosanoids in aged rats. Biochim Biophys Acta 1851(2):203-209. doi:10.1016/j. bbalip.2014.10.009

15. Bazan NG (2009) Neuroprotectin D1-mediated anti-inflammatory and survival signaling in stroke, retinal degenerations, and Alzheimer's disease. J Lipid Res 50(Suppl):S400-S405. doi:10.1194/j1r.R800068-JLR200

16. Lukiw WJ, Bazan NG (2008) Docosahexaenoic acid and the aging brain. J Nutr 138(12):2510-2514. doi:10.3945/jn.108.096016

17. Hashimoto M, Hossain S, Shimada T, Sugioka K, Yamasaki H, Fujii Y, Ishibashi Y, Oka J et al (2002) Docosahexaenoic acid provides protection from impairment of learning ability in Alzheimer's disease model rats. J Neurochem 81(5):1084-1091

18. Bazan NG (2005) Neuroprotectin D1 (NPD1): a DHA-derived mediator that protects brain and retina against cell injury-induced oxidative stress. Brain Pathol 15(2):159-166

19. Bazan NG (2003) Synaptic lipid signaling: significance of polyunsaturated fatty acids and platelet-activating factor. J Lipid Res 44(12):2221-2233. doi:10.1194/jlr.R300013-JLR200

20. Sun GY, Xu J, Jensen MD, Simonyi A (2004) Phospholipase A2 in the central nervous system: implications for neurodegenerative diseases. J Lipid Res 45(2):205-213. doi:10.1194/jlr.R300016JLR200

21. Rapoport SI, Ramadan E, Basselin M (2011) Docosahexaenoic acid (DHA) incorporation into the brain from plasma, as an in vivo biomarker of brain DHA metabolism and neurotransmission. Prostaglandins \& other lipid mediators 96(1-4):109-113. doi:10.1016/j.prostaglandins.2011.06.003

22. Gattaz WF, Talib LL, Schaeffer EL, Diniz BS, Forlenza OV (2013) Low platelet iPLA activity predicts conversion from mild cognitive impairment to Alzheimer's disease: a 4-year follow-up study. J Neural Transm. doi:10.1007/s00702-013-1088-8

23. Shalini SM, Chew WS, Rajkumar R, Dawe GS, Ong WY (2014) Role of constitutive calcium-independent phospholipase $\mathrm{A} 2$ beta in hippocampo-prefrontal cortical long term potentiation and spatial working memory. Neurochem Int 78C:96-104. doi:10.1016/j. neuint.2014.08.006

24. Wolf MJ, Izumi Y, Zorumski CF, Gross RW (1995) Longterm potentiation requires activation of calcium-independent phospholipase A2. FEBS Lett 377(3):358-362. doi:10.1016 /0014-5793(95)01371-7

25. Fujita S, Ikegaya Y, Nishikawa M, Nishiyama N, Matsuki N (2001) Docosahexaenoic acid improves long-term potentiation attenuated 
by phospholipase a(2) inhibitor in rat hippocampal slices. Br J Pharmacol 132(7):1417-1422. doi:10.1038/sj.bjp.0703970

26. Mazzocchi-Jones D (2015) Impaired corticostriatal LTP and depotentiation following iPLA2 inhibition is restored following acute application of DHA. Brain Res Bull 111:69-75. doi:10.1016/j.brainresbull.2014.12.010

27. Yurko-Mauro K, McCarthy D, Rom D, Nelson EB, Ryan AS, Blackwell A, Salem N Jr, Stedman M et al (2010) Beneficial effects of docosahexaenoic acid on cognition in age-related cognitive decline. Alzheimer's \& dementia: the journal of the Alzheimer's Association 6(6):456-464. doi:10.1016/j.jalz.2010.01.013

28. Calon F, Lim GP, Yang F, Morihara T, Teter B, Ubeda O, Rostaing P, Triller A et al (2004) Docosahexaenoic acid protects from dendritic pathology in an Alzheimer's disease mouse model. Neuron 43(5):633-645. doi:10.1016/j.neuron.2004.08.013

29. Cole GM, Frautschy SA (2006) Docosahexaenoic acid protects from amyloid and dendritic pathology in an Alzheimer's disease mouse model. Nutr Health 18(3):249-259

30. Lim GP, Calon F, Morihara T, Yang F, Teter B, Ubeda O, Salem N Jr, Frautschy SA et al (2005) A diet enriched with the omega-3 fatty acid docosahexaenoic acid reduces amyloid burden in an aged Alzheimer mouse model. J Neurosci Off J Soc Neurosci 25(12): 3032-3040. doi:10.1523/JNEUROSCI.4225-04.2005

31. Paxinos G, Watson C (1998) The rat brain in stereotaxic coordinates. Academic, New York

32. Van Pelt LF (1977) Ketamine and xylazine for surgical anesthesia in rats. J Am Vet Med Assoc 171(9):842-844

33. Livak KJ, Schmittgen TD (2001) Analysis of relative gene expression data using real-time quantitative PCR and the 2(-Delta Delta $\mathrm{C}(\mathrm{T})$ ) method. Methods 25(4):402-408. doi:10.1006 /meth.2001.1262

34. Lim EP, Tan CH, Jay TM, Dawe GS (2010) Locus coeruleus stimulation and noradrenergic modulation of hippocampo-prefrontal cortex long-term potentiation. The international journal of neuropsychopharmacology/official scientific journal of the Collegium Internationale Neuropsychopharmacologicum 13(9): 1219-1231. doi:10.1017/S1461145709991131

35. Deacon RM, Rawlins JN (2006) T-maze alternation in the rodent. Nat Protoc 1(1):7-12. doi:10.1038/nprot.2006.2

36. Kuhn H, Barnett J, Grunberger D, Baecker P, Chow J, Nguyen B, Bursztyn-Pettegrew H, Chan H et al (1993) Overexpression, purification and characterization of human recombinant 15lipoxygenase. Biochim Biophys Acta 1169(1):80-89

37. Romanov S, Wiesner R, Myagkova G, Kuhn H, Ivanov I (2006) Affinity labeling of the rabbit 12/15-lipoxygenase using azido derivatives of arachidonic acid. Biochemistry 45(11):3554-3562. doi:10.1021/bi052152i

38. Park CK, Xu ZZ, Liu T, Lu N, Serhan CN, Ji RR (2011) Resolvin $\mathrm{D} 2$ is a potent endogenous inhibitor for transient receptor potential subtype V1/A1, inflammatory pain, and spinal cord synaptic plasticity in mice: distinct roles of resolvin D1, D2, and E1. J Neurosci Off J Soc Neurosci 31(50):18433-18438. doi:10.1523 /JNEUROSCI.4192-11.2011

39. Huang L, Wang CF, Serhan CN, Strichartz G (2011) Enduring prevention and transient reduction of postoperative pain by intrathecal resolvin D1. Pain 152(3):557-565. doi:10.1016/j. pain.2010.11.021

40. Lima-Garcia JF, Dutra RC, da Silva K, Motta EM, Campos MM, Calixto JB (2011) The precursor of resolvin D series and aspirintriggered resolvin D1 display anti-hyperalgesic properties in adjuvant-induced arthritis in rats. Br J Pharmacol 164(2):278-293. doi:10.1111/j.1476-5381.2011.01345.x

41. Fuster J (2008) The prefrontal cortex. Access Online via Elsevier

42. Floresco SB, Seamans JK, Phillips AG (1997) Selective roles for hippocampal, prefrontal cortical, and ventral striatal circuits in radial-arm maze tasks with or without a delay. J Neurosci 17(5):1880-1890

43. Lee I, Kesner RP (2003) Time-dependent relationship between the dorsal hippocampus and the prefrontal cortex in spatial memory. $\mathrm{J}$ Neurosci Off J Soc Neurosci 23(4):1517-1523

44. Laroche S, Jay TM, Thierry AM (1990) Long-term potentiation in the prefrontal cortex following stimulation of the hippocampal CA1/subicular region. Neurosci Lett 114(2):184-190

45. Courtney SM, Petit L, Maisog JM, Ungerleider LG, Haxby JV (1998) An area specialized for spatial working memory in human frontal cortex. Science 279(5355):1347-1351

46. Dember WN, Fowler H (1958) Spontaneous alternation behavior. Psychol Bull 55(6):412-428

47. Dudchenko PA (2004) An overview of the tasks used to test working memory in rodents. Neurosci Biobehav Rev 28(7):699-709. doi:10.1016/j.neubiorev.2004.09.002

48. Seamans JK, Floresco SB, Phillips AG (1995) Functional differences between the prelimbic and anterior cingulate regions of the rat prefrontal cortex. Behav Neurosci 109(6):1063-1073

49. Jay TM, Burette F, Laroche S (1995) NMDA receptor-dependent long-term potentiation in the hippocampal afferent fibre system to the prefrontal cortex in the rat. Eur J Neurosci 7(2):247-250

50. Chytrova G, Ying Z, Gomez-Pinilla F (2010) Exercise contributes to the effects of DHA dietary supplementation by acting on membrane-related synaptic systems. Brain Res 1341:32-40. doi:10.1016/j.brainres.2009.05.018

51. Cao D, Kevala K, Kim J, Moon HS, Jun SB, Lovinger D, Kim HY (2009) Docosahexaenoic acid promotes hippocampal neuronal development and synaptic function. J Neurochem 111(2):510-521. doi:10.1111/j.1471-4159.2009.06335.x

52. Bach SA, de Siqueira LV, Muller AP, Oses JP, Quatrim A, Emanuelli T, Vinade L, Souza DO et al (2014) Dietary omega-3 deficiency reduces BDNF content and activation NMDA receptor and Fyn in dorsal hippocampus: implications on persistence of long-term memory in rats. Nutr Neurosci 17(4):186-192. doi:10.1179/1476830513Y.0000000087

53. Dyall SC, Michael GJ, Whelpton R, Scott AG, Michael-Titus AT (2007) Dietary enrichment with omega-3 polyunsaturated fatty acids reverses age-related decreases in the GluR2 and NR2B glutamate receptor subunits in rat forebrain. Neurobiol Aging 28(3): 424-439. doi:10.1016/j.neurobiolaging.2006.01.002

54. Xu ZZ, Zhang L, Liu T, Park JY, Berta T, Yang R, Serhan CN, Ji RR (2010) Resolvins RvE1 and RvD1 attenuate inflammatory pain via central and peripheral actions. Nat Med 16(5):592-597 . doi:10.1038/nm.2123591p following 597

55. Bang S, Yoo S, Yang TJ, Cho H, Kim YG, Hwang SW (2010) Resolvin D1 attenuates activation of sensory transient receptor potential channels leading to multiple antinociception. Br J Pharmacol 161(3):707-720. doi:10.1111 /j.1476-5381.2010.00909.x

56. Krishnamoorthy S, Recchiuti A, Chiang N, Yacoubian S, Lee CH, Yang R, Petasis NA, Serhan CN (2010) Resolvin D1 binds human phagocytes with evidence for proresolving receptors. Proc Natl Acad Sci U S A 107(4):1660-1665. doi:10.1073/pnas.0907342107

57. Abdelmoaty S, Wigerblad G, Bas DB, Codeluppi S, FernandezZafra T, El-Awady el S, Moustafa Y, Abdelhamid Ael D et al (2013) Spinal actions of lipoxin A4 and 17(R)-resolvin D1 attenuate inflammation-induced mechanical hypersensitivity and spinal TNF release. PLoS One 8(9):e75543. doi:10.1371/journal. pone. 0075543

58. Bang S, Yoo S, Yang TJ, Cho H, Hwang SW (2012) 17(R)-resolvin D1 specifically inhibits transient receptor potential ion channel vanilloid 3 leading to peripheral antinociception. $\mathrm{Br} \mathrm{J}$ Pharmacol 165(3):683-692. doi:10.1111/j.1476-5381.2011.01568.x 